\section{Violent behaviour in schizophrenia}

\author{
Retrospective study of four independent \\ samples from Prague, 1949 to 2000
}

JAN VEVERA, ALAN HUBBARD, ARNOŠT VESELÝ and HANA PAPEŽOVÁ

\author{
Background A number of studies have \\ reported increased violence in patients \\ with schizophrenia.
}

\begin{abstract}
Aims To determine the prevalence of violence among those with schizophrenia in samples from 1949, 1969, 1989 and 2000 in Prague (Czech Republic) and to examine trends in this behaviour.
\end{abstract}

Method Records from 404 patients meeting DSM-IV criteria for schizophrenia were screened for violence (defined as 3 points on the Modified Overt Aggression Scale) from the first observed psychotic symptoms until the time of latest available information.

Results Logistic regression revealed a marginally significant increase in violence only in the 2000 cohort. Overall, violence was associated with schizophrenia in 41.8\% of men and $32.7 \%$ of women, with no association between substance misuse and violence.

\section{Conclusions The violence rate found in our sample is expected to remain stable over time under stable conditions. \\ Substance misuse is not the leading cause of violence among those with schizophrenia.}

Declaration of interest None. Funding detailed in Acknowledgements.
Although most people with schizophrenia are not violent, there appears to be a relationship between this disorder and violence (Walsh et al, 2004). The risk of violence is further increased by associated substance misuse (Lindqvist \& Allebeck, 1990). The MacArthur Study (Steadman et al, 1998) suggested that substance misuse is responsible for the increase in violent behaviour in those with schizophrenia compared with the general population. Evidence from North America and Europe (Hodgins, 2001) suggests that the risk of violence from psychiatric patients in the community and in hospitals has been increasing. However, an Australian study (Wallace et al, 2004) reported that increasing violence in patients with schizophrenia is merely a reflection of an increase in violence in the general population. We examine whether there has been an increase in the prevalence of violence among those with schizophrenia in Prague, Czech Republic, between 1949 and 2000, and analyse the relationships between violence, substance misuse and gender.

\section{METHOD}

\section{Patient selection}

We collected data on clinical, epidemiological and socio-demographic variables from four independent samples of in-patients $(n=572)$. Only those meeting DSM-IV criteria for schizophrenia (American Psychiatric Association, 1994) were included in the study. The four samples consisted of patients admitted to the inpatient unit of the Psychiatric Clinic, Charles University, 1st Medical Faculty, Prague, with the diagnosis of schizophrenia at any time between 1 January 1949 and 31 December 1949 (1949 cohort, $n=164$ ), 1 January 1969 and 31 December 1969 (1969 cohort, $n=83$ ), 1 January 1989 and 31 December 1989 (1989 cohort, $n=85$ ) and 1 January 2000 and 31 December
2000 (2000 cohort, $n=72$ ). The clinic admitted patients from a catchment area encompassing one district in the centre of Prague (Prague 2). Patients who needed long-term hospitalisation were transferred to specialised institutions only after shortterm hospitalisation in this hospital. The psychiatric clinic was the only psychiatric in-patient facility for this area. Our patient population was all White. Selection of patients was based on information at discharge that was collected using the same format over the period covered by the study. The study was approved by the ethics committee of the Medical Faculty, Charles University.

There were no major organisational changes during the study period. Deinstitutionalisation policies were not applied during the 1960s but the number of inhabitants in the catchment area decreased by about half $(53 \%)$ between 1950 and 1970 . There were 174500 inhabitants in Prague 2 in 1950, and 92200, 61800 and 51000 in the years 1970, 1991 and 2001, respectively (Czech Statistical Office, 2003a). Commercial building in the former residential blocks occurred across the area and was unrelated to the characteristics of the patients living there, so we consider the process to be random. The population decrease is consistent with the fact that between 1949 and 1969 the number of hospitalised patients with schizophrenia decreased to about half the number in 1949.

\section{Evaluation methods}

Records from all 572 patients were reviewed by an experienced psychiatrist (J.V.). Only those patients $(n=404)$ meeting the DSM-IV criteria for schizophrenia (295.1-3, 295.6 and 295.9) were included in the study. The review procedures were identical for all samples. All charts available were located and reviewed. For patients who had moved, updated addresses were obtained from the Central Register of the Czech Population, and new records were obtained from the psychiatric facility in the new catchment areas whenever the patient was rehospitalised.

Information on violence of patients in the community and hospital during the study period was acquired from medical records. We recorded all aggressive attacks since the first observed psychotic symptoms. The duration of observation was defined as the time between the first 
observed psychotic symptoms and the time of the last available information. Aggressive behaviour was evaluated using the Modified Overt Aggression Scale (MOAS; Kay et al, 1988). The MOAS measures four categories of aggression: (1) verbal aggression, (2) physical aggression against self, (3) physical aggression against objects and (4) physical aggression against other people. The most severe aggressive event within each category is multiplied by its designated weight factor and then summed to yield a total aggression score. Patients were considered to be violent if they expressed overt and intentional physically aggressive behaviour against another person or a verbal threat with an accompanying weapon, with a total aggression score of 3 or more points on the MOAS. We selected this relatively high threshold on the MOAS to avoid underreporting of violence, because verbal violence or minor attacks with minimal consequences are less likely to be reported (Volavka, 2002). Information on substance misuse or dependency was acquired from medical records. That information was part of the diagnostic interview throughout the study period. Underreporting of substance misuse is common, however we typically have information covering a period of 15-20 years from six admissions and discharges records (Table 1), which should make our data more reliable. Detailed evaluations of violent incidents were not available for the patients from the 1949 and 1969 cohorts; a typical note was: 'physically aggressive over the last 3 days' or 'repeated heteroaggression in anamnesis'. This statement shows that the patient reached the threshold ( 3 points on the MOAS) but does not provide information on the target and intensity of attacks. In the 1989 and 2000 cohorts the aggressors or their psychiatrists were interviewed in every single case and the target was specified.

Patients who committed one or more assaults in one 2-week period were classified as transiently violent. Patients who committed at least two assaults in at least two different 2-week periods were classified as persistently violent.

\section{Statistical analysis}

Logistic regression was used to investigate trends in the prevalence of violence among patients with schizophrenia. Presence or absence of violence served as a binary variable in the logistic regression; cohort was entered both as an unordered categorical variable using dummy variables and as an ordered variable $(1=1949, \quad 2=1969$ $3=1989,4=2000)$ to test for trends in violence. We performed analyses both unadjusted and adjusted for both length of observation (by simply including a linear term of the number of years a patient was followed from the first observed psychotic symptoms until the time of latest available information) and for gender. Observation time was adjusted for because more recent cohorts would typically have less observation time and this will confound any associations with cohort and trends in violence. We also used logistic regression to examine the association of violence with both gender and substance misuse, in each case adjusting for length of observation.

\section{RESULTS}

\section{Prevalence of violence}

Data on gender, age, hospitalisation and substance misuse are shown in Table 1 . The prevalence of violence since the first episode of schizophrenia was $34.8 \%$, $44.6 \%, 32.9 \%$ and $44.4 \%$ in the 1949 , 1969, 1989 and 2000 samples respectively (Table 2). The overall prevalence of violence was $41.8 \%$ for men and $32.7 \%$ for women (Fig. 1). There was only a marginally significant difference in violence for women $v$. men (adjusted OR $=0.65,95 \%$ CI 0.43-1.00). Exact dates of violent attacks were available for patients in the 1989 and 2000 cohorts only. Frequency of attacks for those cohorts is shown in Table 3.

\section{Trends in prevalence of violence}

Using unadjusted logistic regression, there was no significant linear trend in the prevalence of violence among the cohort members between 1949 and 2000 $(\mathrm{OR}=1.08$, 95\% CI 0.91-1.29). However when adjusting for length of observation and gender, there was a marginally

Table I Gender, age, hospitalisation and substance misuse in the four cohorts with schizophrenia

\begin{tabular}{|c|c|c|c|c|c|c|c|c|}
\hline & \multicolumn{8}{|c|}{ Cohort } \\
\hline & \multicolumn{2}{|c|}{$1949(n=164)$} & \multicolumn{2}{|c|}{$1969(n=83)$} & \multicolumn{2}{|c|}{$1989(n=85)$} & \multicolumn{2}{|c|}{$2000(n=72)$} \\
\hline & $\begin{array}{c}\text { Males } \\
(n=89,54 \%)\end{array}$ & $\begin{array}{c}\text { Females } \\
(n=75,46 \%)\end{array}$ & $\begin{array}{c}\text { Males } \\
(n=48,58 \%)\end{array}$ & $\begin{array}{c}\text { Females } \\
(n=35,42 \%)\end{array}$ & $\begin{array}{c}\text { Males } \\
(n=53,62 \%)\end{array}$ & $\begin{array}{c}\text { Females } \\
(n=32,38 \%)\end{array}$ & $\begin{array}{c}\text { Males } \\
(n=49,68 \%)\end{array}$ & $\begin{array}{c}\text { Females } \\
(n=23,32 \%)\end{array}$ \\
\hline Age at onset, years: mean (s.d.) & $25.4(9.3)$ & $29.9(10.1)$ & $22.3(6.2)$ & $25.4(9.4)$ & $25.2(8.4)$ & $25.3(8.0)$ & $22.9(7.6)$ & $27.2(9.0)$ \\
\hline $\begin{array}{l}\text { Age at index hospitalistion, years: } \\
\text { mean (s.d.) }\end{array}$ & $30.5(9.9)$ & $33.3(10.9)$ & $29.3(9.3)$ & $32.9(13.6)$ & $37.2(12.1)$ & $38.9(11.2)$ & $32.0(11.8)$ & $40.5(13.3)$ \\
\hline Observation, years: mean (s.d.) & $24.7(16.7)$ & $24.9(15.3)$ & $22.1(9.6)$ & $21.9(6.7)$ & I3.7 (9.75) & $14.6(10.1)$ & $10.9(9.5)$ & $14.35(10.1)$ \\
\hline $\begin{array}{l}\text { Duration of first hospitalisation, } \\
\text { days: mean (s.d.) }\end{array}$ & $70(48)$ & $97(258)$ & $104(66)$ & $87(70)$ & $12 \mid(124)$ & $60(46)$ & $65(47)$ & $58(42)$ \\
\hline $\begin{array}{l}\text { Duration of all hospitalisation, } \\
\text { years: mean (s.d.) }\end{array}$ & $6.24(10.38)$ & $4.42(7.87)$ & $2.83(2.82)$ & $4.11(5.10)$ & $2.04(1.66)$ & $1.12(0.99)$ & $0.73(I .19)$ & $0.74(1.12)$ \\
\hline $\begin{array}{l}\text { Number of hospitalisations: } \\
\text { mean (s.d.) }\end{array}$ & $6.31(5.05)$ & $5.03(4.38)$ & $10.02(8.54)$ & $7.30(6.35)$ & 7.87 (5.99) & $6.26(4.34)$ & $6.09(4.87)$ & $6.36(5.69)$ \\
\hline Substance misuse and & $\mathrm{I}(\mathrm{I} . \mathrm{I})$ & $2(2.7)$ & $4(8.3)$ & $2(5.7)$ & $5(9.4)$ & $I(3 . I)$ & II (22.4) & $3(13)$ \\
\hline dependency, $n(\%)$ & \multicolumn{2}{|c|}{$3(1.8)$} & \multicolumn{2}{|c|}{$6(7.2)$} & \multicolumn{2}{|c|}{$6(7.1)$} & \multicolumn{2}{|c|}{$14(19.4)$} \\
\hline
\end{tabular}


Table 2 Distribution of aggression in four schizophrenic cohorts by gender

\begin{tabular}{|c|c|c|c|c|c|}
\hline \multirow[t]{2}{*}{ Aggression } & \multicolumn{4}{|c|}{ Cohort } & \multirow[t]{2}{*}{ Total violence } \\
\hline & 1949 & 1969 & 1989 & 2000 & \\
\hline Females, $n$ (\%) & $20(26.7)$ & $14(40.0)$ & II (34.4) & $9(39.1)$ & $54(32.7)$ \\
\hline Males, $n(\%)$ & $37(4 \mid .6)$ & $23(47.9)$ & $17(32.1)$ & $23(46.9)$ & $100(4 I .8)$ \\
\hline Total, $n(\%)$ & $57(34.8)$ & $37(44.6)$ & $28(32.9)$ & $32(44.4)$ & 154 (38.I) \\
\hline $\mathrm{OR}^{\prime}(95 \% \mathrm{Cl})$ & I.0 (reference) & $1.63(0.94-2.84)$ & I. $14(0.62-2.08)$ & $2.01(1.07-3.75)$ & \\
\hline
\end{tabular}

OR, odds ratio.

I. Odds ratios from logistic regression adjusted for observation years and gender.

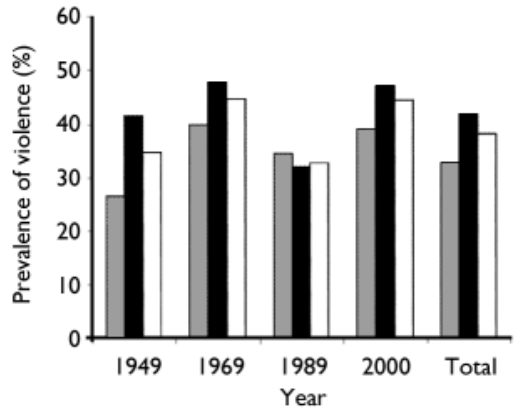

Fig. I Aggression in four cohorts of patients with schizophrenia according to gender; $\square$ female;

$\square$ male; $\square$ total. significant increasing trend in the probability of violence over the four cohorts $(\mathrm{OR}=1.21$, $95 \%$ CI 0.99-1.47). The change in significance was because the more recent cohorts had less observation time.

Repeating the adjusted analyses on the categorical 1949 cohort (see Table 2), we found a significant difference only when comparing the 2000 and 1949 cohorts $(\mathrm{OR}=2.01,95 \%$ CI 1.07-3.75). Although the trend in violence appeared more pronounced among women than men, the difference in trends was not statistically significant (test of interaction $P=0.37$ ).
Table 3 Frequency of assaults in 1989 and 2000 cohorts

\begin{tabular}{lccccc}
\hline & $\begin{array}{c}\text { One } \\
\text { assault }\end{array}$ & $\begin{array}{c}\text { Two } \\
\text { assaults }\end{array}$ & $\begin{array}{c}\text { Three } \\
\text { assaults }\end{array}$ & $\begin{array}{c}\text { Four assaults } \\
\text { and more }\end{array}$ & Total \\
\hline $\begin{array}{l}\text { Males } \\
\text { Number of patients }\end{array}$ & 171 & 7 & 9 & 7 & 40 \\
$\begin{array}{l}\text { Duration of illness at time of assault, } \\
\text { years:mean (s.d.) }\end{array}$ & $5.6(7.3)$ & $8.2(8.5)$ & $7.4(6.5)$ & $3.6(4)$ & $6(6.8)$ \\
$\begin{array}{l}\text { Age at violent assault, years:mean (s.d.) } \\
\text { Females }\end{array}$ & $27.6(10.3)$ & $36(12.9)$ & $28.8(10.8)$ & $31.6(11.5)$ & $30.1(10.9)$ \\
$\quad \begin{array}{l}\text { Number of patients } \\
\text { Duration of illness at time of assault, }\end{array}$ & $4(6.5)$ & 0 & $10.7(7.6)$ & 4 & $5.0(6.7)$ \\
$\begin{array}{l}\text { years:mean (s.d.) } \\
\text { Age at violent assault, years:mean (s.d.) }\end{array}$ & $31.4(11.7)$ & 0 & $31.3(5.1)$ & 39 & $31.8(10.9)$ \\
\hline
\end{tabular}

I. Of these 17 patients, 7 were consistently violent for more than 14 days and were counted as persistently violent.

Table 4 Victims of assaults by male and female patients in the 1989 and 2000 cohorts

\begin{tabular}{lccc}
\hline Number of assaults & Male $(n=40)$ & Female $(n=20)$ & Total $(n=60)$ \\
\hline Total & 148 & 44 & 192 \\
Family, $n(\%)$ & $70(47)$ & $23(52)$ & $92(48)$ \\
Staff, $n(\%)$ & $40(27)$ & $12(27)$ & $52(27)$ \\
Stranger, $n(\%)$ & $27(18)$ & $7(16)$ & $33(17)$ \\
Fellow patient, $n(\%)$ & $1(0.7)$ & $2(5)$ & $4(2)$ \\
Not known, $n(\%)$ & $10(7)$ & $(0)$ & $11(6)$ \\
\hline
\end{tabular}

\section{Victims of violence - 1989 and 2000 cohorts only}

Only one person was hospitalised as a result of an attack by a patient from the 1989 and 2000 cohorts. There was one death: a patient threw a female from the window of his apartment on the first occasion he met her. This is the only murder reported as a result of an attack by any of the patients studied (1949-2000). Victims of all assaults by the 1989 and 2000 cohorts are described in Table 4.

\section{Prevalence of violence and substance misuse}

There was a history of comorbid substance misuse disorders (mostly alcohol 305.0, 303.9 , with only two cases of sedative and anxiolytic drug misuse (304.1 and 305.4) and one case of trihexyphenidyl misuse) in $1.8 \%, 7.2 \%$ and $7.1 \%$ of patients from the 1949,1969 and 1989 cohorts respectively. In the 2000 cohort the prevalence of substance misuse was $19.4 \% \quad$ (14 patients). Only $4.2 \%$ of patients were diagnosed with alcohol misuse. One female patient $(1.4 \%)$ misused sedatives and $13.8 \%$ of patients misused illicit drugs. Cannabis misuse was found in $5.6 \%$ of patients, amphetamine misuse in $1.4 \%$ and polysubstance misuse in $6.9 \%$.

When data from all four cohorts were analysed, neither the unadjusted nor adjusted (for categorical cohort and gender) associations between substance misuse and violence were statistically significant (adjusted $\mathrm{OR}=0.78,95 \%$ CI $0.34-1.82$ ). The small numbers of violent offenders did not allow us to perform meaningful statistical analysis for any of the cohorts independently.

\section{Duration of hospitalisation}

There were no differences in the duration of the first hospitalisation and the cumulative duration of all hospitalisations when adjusted for observation years. Eighty-three patients from the 1949 cohort never received antipsychotics. These had markedly longer $(P<0.001)$ total duration of hospitalisation $(9.23$ years; s.d. $=11.54)$ than patients who received antipsychotics (1.74 years; s.d.=4.04).

\section{DISCUSSION}

In contrast to epidemiological studies from the USA and Western Europe, we did not find an increase in the prevalence of 
violence among those with schizophrenia in the Czech Republic between 1949 and 1989. After adjusting for length of observation and gender, a marginally higher prevalence of violence was reported in the 2000 sample.

In the USA fragmentation of care is thought to be responsible for an increasing rate of violence (Hogan, 2003). Similarly we hypothesised that fragmentation of care in the Czech Republic, which occurred as a consequence of the unsuccessful transformation of health services (Zacek, 1997), as well as gaps in providing integrated care (Vevera, 2004), were probably responsible for increases in violence in 2000 .

\section{Violence among patients with schizophrenia}

The overall prevalence of violence was $42 \%$ for men and $33 \%$ for women. Only a weak association was found between gender and violence which is similar to other recent studies (Robbins et al, 2003).

\section{Victims of violent assaults - 1989 and 2000 cohorts only}

Analysis of victims of violent assaults shows that family members were involved in half of the assaults committed by male as well as female offenders. Strangers were attacked in $17 \%$ of assaults. This evidence further supports previous findings (Steadman et al, 1998; Milton et al, 2001) that families are the major victims. Unfortunately we do not have data on victimisation among our patients with schizophrenia, but there is evidence that psychiatric patients are more likely to end up as victims rather than perpetrators of violent acts (Walsh et al, 2003).

\section{Duration of hospitalisation}

Introduction of new treatments, particularly antipsychotic medication in the mid1950 s, allowed the cure and amelioration of psychotic symptoms. Hence the duration of hospitalisation was markedly longer (9.23 years) for those patients from the 1949 cohort who never received antipsychotic pharmacotherapy compared with those who used antipsychotics (1.74 years).

There were no differences in the duration of the first hospitalisation and the cumulative duration of all hospitalisations when adjusted for observation years.

\section{Substance misuse and schizophrenia}

The comorbidity of schizophrenia and substance misuse from 1949 to 1989 in our study ranged from 2 to $7 \%$ and was markedly lower than in studies from the USA and Western Europe, where lifetime rates of any misuse have ranged between 40 and $60 \%$ (Regier et al, 1990; Cantor-Graae et al, 2001). The lowest prevalence of alcohol misuse found in the 1949 cohort was probably influenced by the lower availability of alcohol during the Second World War, but the low prevalence of alcohol misuse was consistent throughout the study. We hypothesise that no problems with homelessness, good access to free or government-provided healthcare and a high level of supervision by state authorities have protected patients from deteriorating into substance misuse. Paradoxically patients with schizophrenia could benefit from the high level of control typical of a totalitarian state. After the fall of the communist regime in 1989, the prevalence of alcohol misuse remained stable but the misuse of illicit drugs increased significantly. In our 2000 sample we found a rate of substance misuse of $19.4 \%$. Since only $4.2 \%$ of patients misuse alcohol the availability of illicit street drugs was responsible for this increase. Alcohol misuse was markedly lower than in the general population, in which $18.5 \%$ of men and $3.5 \%$ of women reported drinking problems (measured as 2 or more points on the CAGE questionnaire) according to a study conducted in 1999-2000 (Bobak et al, 2004). By tradition the Czech Republic has a high alcohol consumption (9.9 litres of pure alcohol in the year 2000) with 160 litres of beer consumed per citizen in 2000, which make it 'first' in beer consumption (Czech Statistical Office, 2003b). Data from 1999 show that $17 \%$ of adults reported lifetime drug misuse (Csemy et al, 2002). These data show that those with schizophrenia do not have higher rates of substance misuse than the general population.

\section{Substance misuse and violence}

Surprisingly no association was found between substance misuse and violence. Data from the MacArthur Study (Steadman et al, 1998) indicate that substance misuse is responsible for the increased rate of violence among psychiatric patients. Misuse of legal drugs (alcohol) robustly correlated with violence; however, occasional use of alcohol appeared to be a protective factor compared with abstinent patients with schizophrenia (Volavka et al, 1997). It could be hypothesised that those drinking occasionally have higher levels of social skills, which make them less likely to be violent. A study conducted in Canada, Germany, Finland and Sweden also did not find an increased risk of violence among those with schizophrenia and substance misuse (Hodgins et al, 2003). A recent Australian study also cast doubt on the role of substance misuse alone in accounting for the higher rates of offending among those with schizophrenia (Wallace et al, 2004).

Together these findings suggest that in a stable healthcare system substance misuse is not the leading cause of violence among patients with schizophrenia. Preventing patients from misusing substances is not sufficient to reduce the prevalence of violence. Strategies aimed at disordered impulse control and psychopathic characteristics, which now seem to be the leading causes of violence among those with schizophrenia (Nolan et al, 1999, 2003), could decrease violence. Psychotherapeutic techniques, such as cognitive-behavioural treatment, which target anger-regulatory mechanisms are already showing promising results in patients with post-traumatic stress disorder, psychoses and developmental disabilities (Chemtob et al, 1997; Novaco \& Taylor, 2004). Treatment with atypical antipsychotic medications, which appear to have ameliorative effects on cognitive symptoms among patients with schizophrenia (Bilder et al, 2002), may help to reduce confusion-related assaults.

Given the low number of those with associated substance misuse, we hypothesise that the aggressive behaviour in our cohorts is primarily linked to the nature of the underlying psychopathological condition, namely disordered impulse control, psychopathy and psychotic symptoms. This rate of aggression would be expected to remain stable over time with stable conditions, for example a patient's relatively stable socioeconomic level, a stable healthcare system and limited access to street drugs.

\section{ACKNOWLEDGEMENTS}

The study was funded by NIH Fogarty, Finance and Mental Health Services in Czech Republic SPH, and the University of California, Berkeley (D43 TW058I0, MSM IIII0000I and IGA 7549-3). 


\section{REFERENCES}

American Psychiatric Association (1994) Diagnostic and Statistical Manual of Mental Disorders (4th edn) (DSM-IV). Washington, DC: APA.

Bilder, R. M., Goldman, R. S., Volavka, J., et al (2002) Neurocognitive effects of clozapine, olanzapine, risperidone, and haloperidol in patients with chronic schizophrenia or schizoaffective disorder. American Journal of Psychiatry, 159, 1018-1028.

Bobak, M., Room, R., Pikhart, H., et al (2004) Contribution of drinking patterns to differences in rates of alcohol related problems between three urban populations. Journal of Epidemiology and Community Health, 58, 238-242.

Cantor-Graae, E., Nordstrom, L. G. \& McNeil, T. F. (200I) Substance abuse in schizophrenia: a review of the literature and a study of correlates in Sweden. Schizophrenia Research, 48, 69-82.

Chemtob, C. M., Novaco, R.W., Hamada, R. S., et al (1997) Cognitive-behavioral treatment for severe anger in posttraumatic stress disorder. Journal of Consulting and Clinical Psychology, 65, 184-189.

Csemy, L., Kubicka, L. \& Nociar, A. (2002) Drug scene in the Czech Republic and Slovakia during the period of transformation. European Addiction Research, 8, 159-165.

Czech Statistical Office (2003a) Sčitání lidu, domů a bytů 200I. Prague: CSÚ. http: / / www.czso.cz

Czech Statistical Office (2003b) Statistická Ročenka České republiky 2003. Prague: CSÚ. http: // www.czso.cz

Hodgins, S. (200I) The major mental disorders and crime: stop debating and start treating and preventing. International Journal of Law and Psychiatry, 24, 427-446.

Hodgins, S., Hiscoke, U. L., Freese, R. (2003) The antecedents of aggressive behavior among men with schizophrenia: a prospective investigation of patients in community treatment. Behavioral Sciences and the Law, 2I, 523-546.

Hogan, M. F. (2003) The President's New Freedom Commission: recommendations to transform mental health care in America. Psychiatric Services, 54 1467-1474.

Kay, S. R., Wolkenfeld, F. \& Murril, L. M. (1988) Profiles of aggression among psychiatric patients. I. Nature and prevalence. Journal of Nervous and Mental Disease, 176, 539-546.

Lindqvist, P. \& Allebeck, P. (1990) Schizophrenia and crime. A longitudinal follow-up of 644 schizophrenics in Stockholm. British Journal of Psychiatry, I57, 345-350.

Milton, J., Amin, S., Singh, S. P., et al (2001) Aggressive incidents in first-episode psychosis. British Journal of Psychiatry, 178, 433-440.

Nolan, K. A., Volavka, J., Mohr, P., et al (1999) Psychopathy and violent behavior among patients with schizophrenia or schizoaffective disorder. Psychiatric Services, 50, 787-792.

Nolan, K. A., Czobor, P., Roy, B. B., et al (2003) Characteristics of assaultive behavior among psychiatric inpatients. Psychiatric Services, 54, 1012-1016.

Novaco, R. \& Taylor, J. (2004) Assessment of anger and aggression in male offenders with developmental disabilities. Psychological Assessment, 16, 42-50.

\section{CLINICAL IMPLICATIONS}

- There was no increase in violence in our sample of patients with schizophrenia between 1949 and 1989, and only a marginally higher prevalence of violence in the 2000 sample. The violence rate reported in our sample would be expected to remain stable over time and under stable conditions.

- Family members and medical staff are the most frequent victims of violence.

- In a stable healthcare system substance misuse is not the leading cause of violence among those with schizophrenia.

\section{LIMITATIONS}

This is a study of violence among people hospitalised for schizophrenia, not an epidemiological survey of violence among people with schizophrenia in the general population.

- The data were taken from urban psychiatric settings. Rural populations might be different.

- The data-set did not include information on how violence changes over time and whether attacks occurred in the hospital or in the community.

IAN VEVERA, MD, Psychiatric Clinic, Ist Faculty of Medicine, Charles University, Prague, Czech Republic, and School of Public Health, University of California, Berkeley, USA; ALAN HUBBARD, PhD, ARNOŠT VESELÝ, PhD, University of California, Berkeley, USA; HANA PAPEŽOVÁ, MD, Psychiatric Clinic, Ist Faculty of Medicine, Charles University, Prague, Czech Republic

Correspondence: Dr Jan Vevera, Psychiatric Clinic, Ist Faculty of Medicine, Charles University, Ke Karlovu II, Prague 120 00, Czech Republic. E-mail: janvevera@centrum.cz

(First received 27 July 2004, final revision 8 February 2005, accepted 12 February 2005)

Regier, D. A., Farmer, M. E., Rae, D. S., et al (1990) Comorbidity of mental disorders with alcohol and other drug abuse: results from the Epidemiologic Catchment Area (ECA) Study. JAMA, 264, 25II-25I8.

Robbins, P. C., Monahan, J., Silver, E. (2003) Mental disorder, violence, and gender. Law and Human Behavior, 27, 561-571.

Steadman, H. J., Mulvey, E. P., Monahan, J., et al (1998) Violence by people discharged from acute psychiatric inpatient facilities and by others in the same neighborhoods. Archives of General Psychiatry, 55, 393-401.

Vevera, J. (2004) Problems and goals in the US psychiatry and its application for Czech psychiatric care. Ceska a Slovenska Psychiatrie, 4, 134-140.

Volavka, J. (2002) Neurobiology of Violence. Washington DC: American Psychiatric Publishing.

Volavka, J., Laska, E., Baker, S., et al (1997) History of violent behaviour and schizophrenia in different cultures.
Analyses based on the WHO study on Determinants of Outcome of Severe Mental Disorders. British Journal of Psychiatry, I7I, 9-14.

Wallace, C., Mullen, P. E., Burgess, P. (2004) Crimina offending in schizophrenia over a 25 -year period marked by deinstitutionalization and increasing prevalence of comorbid substance use disorders. American Journal of Psychiatry, 161, 716-727.

Walsh, E., Moran, P., Scott, C., et al (2003) Prevalence of violent victimisation in severe mental illness. British Journal of Psychiatry, 183, 233-238.

Walsh, E., Gilvarry, C., Samele, C., et al (2004) Predicting violence in schizophrenia: a prospective study. Schizophrenia Research, 67, 247-252.

Zacek, A. (1997) Failures, problems and hopes in the transformation of health services. I. Causes of erroneous decisions in the beginning phases of transformation. Casopis Lekaru Ceskych, I36, 103-105. 